\title{
EVOLUÇÃO DA PESCARIA INDUSTRIAL DE CAMARÃO-ROSA (Farfantepenaeus brasiliensis e F. paulensis) NA COSTA SUDESTE E SUL DO BRASIL - 1968-1989.
}

\author{
HELIO VALENTINI'; FERNANDO D'INCAO ${ }^{2}$; LUIZ FERNANDO RODRIGUES ${ }^{3}$ E LUIZ FELIPE DUMONT $^{2}$ \\ ${ }^{1}$ Instituto de Pesca, Av. Bartolomeu de Gusmão, 172 - Santos, SP, Brasil. CEP-11030-960 - ipescapm@terra.com.br \\ ${ }^{2}$ Universidade Federal do Rio Grande - Instituto de Oceanografia, Laboratório de Crustáceos Decápodos, Rio Grande - RS - Brasil. CEP: \\ 96201-900 - docdinca@furg.br; felipe-dumont@hotmail.com \\ ${ }^{3}$ CEPSUL/IBAMA, Av. Ministro Victor Konder s/n, Itajaí, SC, Brasil. CEP - 88301-280 - fernando@cepsul.ibama.gov.br
}

\begin{abstract}
RESUMO
Foi analisada a série histórica de dados referentes à frota de arrasteiros de camarão-rosa do Estado de São Paulo para o período de 1968 a 1989, obtidos pelo Instituto de Pesca/SP. Este período foi separado em quatro qüinqüênios (1968-1972; 1973-1977; 1978-1983; 1984-1989) que identificam as diversas fases que caracterizaram a evolução da pescaria com base nos trabalhos de avaliação pesqueira. Uma clara mudança no padrão da pescaria foi observada ao longo dos qüinqüênios analisados. No primeiro período, a elevada CPUE das espécies-alvo sustentava bons rendimentos para a pescaria. Durante esse período, a pesca se distribuiu homogeneamente ao longo da costa do SE/S do Brasil, apresentando esforço de pesca bem distribuído latitudinalmente e concentrado nas profundidades de maior abundância do camarão-rosa (40-80 m). A partir do segundo qüinqüênio, as capturas começam a se concentrar na região central, ainda na faixa de profundidade preferencial do camarão-rosa. Nessa fase da pescaria, é notável a diminuição da abundância relativa ao longo de toda área, reflexo do aumento do esforço de pesca aplicado sobre o estoque, embora os desembarques ainda tenham mantido um nível considerado alto. O terceiro e quarto períodos são caracterizados pela queda na CPUE do estoque. A partir do terceiro qüinqüênio, a frota de arrasteiros passou a buscar novos recursos demersais, ampliando a sua área de atuação para profundidades que não mais refletem a distribuição do camarão-rosa. Como conseqüência dessa mudança no padrão de pesca, outras espécies passaram a ganhar importância nos desembarques, com o esforço migrando para profundidades maiores.
\end{abstract}

PALAVRAS CHAVE: Sudeste e Sul do Brasil, pesca do camarão-rosa, esforço de pesca, distribuição da pescaria, fauna acompanhante

\section{ABSTRACT}

Trends in pink shrimp (Farfantepenaeus brasiliensis and $F$. paulensis) commercial fishery off Southeastern and Southern Brazilian coast - 1968-1989

Long-term data obtained from São Paulo commercial pink shrimp fishery (Instituto de Pesca/SP) was analyzed from 1968-1989. Time series was divided in four different periods (1968-1972; 1973-1977; 1978-1983; 1984-1989), according to the trends observed in fishery assessment. A marked shift in fishery pattern was noticed along the different periods studied. During the first period, the high CPUE values of target species sustained highest yields of the entire period analyzed. The first period was characterized by a widespread distribution of fishing effort off SE/S Brazilian coast, concentrated within the depth range of highest abundance of pink shrimp $(40-80 \mathrm{~m})$. From the second period onwards, a concentration of catches in the central area was observed, even though within the depth distribution of the pink shrimp. During this phase, a marked decrease in relative abundance was noticed all over the distribution area, as a consequence of the increased fishing effort applied. The third and fourth periods were characterized by the low CPUE values. From the third period onwards, trawling fleet began to search for new demersal resources, migrating to the fishing grounds outside pink shrimp distribution area. As a consequence of this shift in the fishery pattern, other species started to became important in the land statistics, and the fishing effort moved offshore.

KEYWORDS: Southeastern and South Brazil, pink shrimp fishery, fishing effort, fishery distribution, bycatch

\section{INTRODUÇÃO}

A pescaria industrial do camarão-rosa no sudeste e sul do Brasil, que por longo período manteve-se como a de maior importância econômica nesta região, tem suas raízes históricas em São Paulo. Essa atividade ganhou grande impulso a partir do final da década de 1960, graças à política de incentivos fiscais à pesca, promovida pelo Governo Federal com a intermediação da extinta SUDEPE-Superintendência do Desenvolvimento da Pesca, autarquia vinculada ao então Ministério da Agricultura.

Esta iniciativa propiciou a duplicação da frota arrasteira de São Paulo (cujo número médio de barcos/mês atuantes passou de 59 em 1966, para 125 em 1972) e, praticamente, promoveu a implantação do segmento produtivo industrial de camarão-rosa em Santa Catarina, que, de 20 em
1968, passou a contar em 1972 com um número médio de quase 90 unidades operando (SUDEPE/PDP, 1974).

Um novo impulso ao crescimento da frota camaroneira ocorreu em meados dos anos 80 , graças aos pontuais benefícios promovidos à economia do País pelo denominado "Plano Cruzado". Nesse sentido, embora àquela época já vigorasse legislação impeditiva de ampliação da frota como medida de contenção do esforço de pesca, foi concedido pelo órgão gestor da atividade, um número considerável de licenças ou permissões "provisórias" (que acabaram ganhando duração permanente) a novas embarcações.

Assim, segundo os registros do DEFOP/SUDEPE (Valentini et al., 1991), em novembro de 1988 existiam 372 embarcações permissionadas para a pesca do camarão-rosa na 
costa sudeste-sul, distribuídas pelos estados do Rio de Janeiro (65 - 17\%), São Paulo (225 - 61\%) e Santa Catarina (82 - 22\%).

Aquela super-dimensionada frota chegou a aplicar um esforço de pesca total estimado em 855 mil horas de arrasto, em 1985 e, em média, 700 mil nos três anos subsequentes (D'Incao et al., 2002). As maiores concentrações encontram-se distribuídas na faixa de 40-60 $\mathrm{m}$ de profundidade.

O crescimento desordenado da frota pesqueira industrial, aliado a outros fatores, como o grande incremento da pesca artesanal e a degradação ambiental nas áreas de criadouro (onde se desenvolve - estrato juvenil do recurso) influenciaram negativamente os níveis de abundância do estoque. Além dos fatores previamente citados, a ineficácia das medidas de ordenamento da pescaria também contribui significativamente para uma situação de colapso por depleção do estoque, já prognosticada por Valentini et al. (1991) e confirmada por D'Incao et al. (2002).

Tal situação pode ser caracterizada pelas estimativas da captura máxima sustentável e da abundância relativa máxima nos períodos 1965-1972, 1973-1986 e 1987-1995, que reduziram-se, respectivamente, de $7165 \mathrm{t}$ para $3049 \mathrm{t}(-57,5 \%)$ e $1963 \mathrm{t}(-35,6 \%)$ e de $12,42 \mathrm{~kg} / \mathrm{h}$ para $4,16 \mathrm{~kg} / \mathrm{h}(-$ $66,5 \%$ ) e 3, $15 \mathrm{~kg} / \mathrm{h}(-24,3 \%)$ (D'Incao et al., 2002).

O presente trabalho busca mostrar a evolução da pescaria industrial de camarão-rosa no sudestesul, com base nos dados originados da frota arrasteira atuante em São Paulo que, no período estudado, compunha $60 \%$ do total de embarcações permissionadas para aquela atividade e operava, no limite de sua capacidade, na mais ampla área de explotação do recurso. Dessa forma, a evolução da pescaria e seus efeitos sobre o estoque adulto de camarão-rosa foram analisados gerando informações importantes para a recuperação do estoque adulto e da pescaria que se encontra colapsada.

\section{MATERIAIS E MÉTODOS}

Utilizaram-se os dados gerados pela frota arrasteira de camarão-rosa baseada em São Paulo, no período de 1968-1989. A frota camaroneira se caracterizava pela boa homogeneidade em suas características físicas (na grande maioria, casco de madeira, TAB de 40-60 t e potência de motor entre 250 e $350 \mathrm{HP}$ ), garantindo a padronização dos dados e a qualidade das informações geradas sobre a pescaria em toda a série histórica estudada (Valentini et al., 1991).

A obtenção e processamento dos mesmos foram executados pela antiga Seção de Controle da Produção Pesqueira/Divisão de Pesca Marítima/Instituto de Pesca (SAA/SP), sediada em Santos-SP. Esse sistema, iniciado na década de 1950, se caracterizou por uma coleta diária (através de entrevistas com os mestres das embarcações e observação direta no momento do desembarque do pescado) das seguintes informações de captura e produção por viagem/barco: data do desembarque; nome e categoria, por tamanho da embarcação; aparelho de captura empregado; local de pesca; distância da costa; profundidade; datas, horários e portos de saída e chegada da viagem; dias de viagem e efetivos de pesca; número e duração média dos lances; produção, total e por espécie de pescado.

Durante o período de 1968-1969, os desembarques dessa frota camaroneira foram efetuados, na quase totalidade, junto aos terminais do antigo Entreposto Federal de Pesca/CIBRAZEM e da Cooperativa Mista de Pesca Nipo-Brasileira, situados, respectivamente, em Santos e Guarujá. Esta centralização dos desembarques permitiu o permanente controle de toda a frota operante naqueles portos e o nível de detalhamento de informações apresentado neste estudo.

No período considerado, a área varrida pela frota controlada estendeu-se da latitude de $18^{\circ} \mathrm{S}$ (acima de Rio Doce/ES) até $33^{\circ} \mathrm{S}$ (próxima ao Arroio Chuí/RS). Para o processamento dos dados a área foi dividida em blocos de 1 grau de lado (latitudes e longitudes) e subdivididos em quadrados de 10 minutos de lado. Os dados referentes a cada quadrado foram plotados considerando $o$ ponto central do mesmo.

À época, dada a inexistência ou pouca utilização de equipamentos de localização por satélite na área de atuação, o informe sobre esta era dado com base em ponto geográfico relevante mais próximo, além da profundidade e distância da costa, no qual a embarcação houvesse permanecido por 
maior tempo em operação de arrasto, no transcorrer da viagem.

O processamento dos dados pela unidade responsável no Instituto de Pesca obedeceu à seguinte seqüência, a partir das planilhas de coleta: crítica dos dados, com demarcação das áreas de pesca; transposição para mapas diários de pesca e fichas individuais por barco/mês; tabulação dos dados de cada pescaria (no caso presente do camarão-rosa oceânico, pelos arrasteiros duplos), para obtenção de quadros mensais e anuais das informações de captura e esforço de pesca, distribuídas por área de operação (blocos de 10' e de $1^{\circ}$ ).

Para o presente estudo, a série histórica de dados da pescaria industrial do camarão-rosa no sudeste-sul pela frota de São Paulo, foi dividida em quatro intervalos correspondentes aos períodos de 1968-1972, 1973-1977, 1978-1983 e 1984-1989. Este parcelamento identifica fases diversas que caracterizaram a evolução daquela pescaria. Essa divisão foi feita com base em trabalhos de avaliação do estoque oceânico e no comportamento da atividade em anos destacáveis; assim como por alterações expressivas nos níveis de captura e esforço correspondentes ao segundo ano de cada sub-período adotado. Os critérios utilizados foram (FIGURA 1): 1969 - ano da maior produção histórica; 1974 - limite da primeira grande queda de produção; 1979 - último ano de um período de pequena recuperação e 1985 - ano do máximo esforço aplicado sobre o recurso (Valentini et al., 1991; D'Incao et.al., 2002).

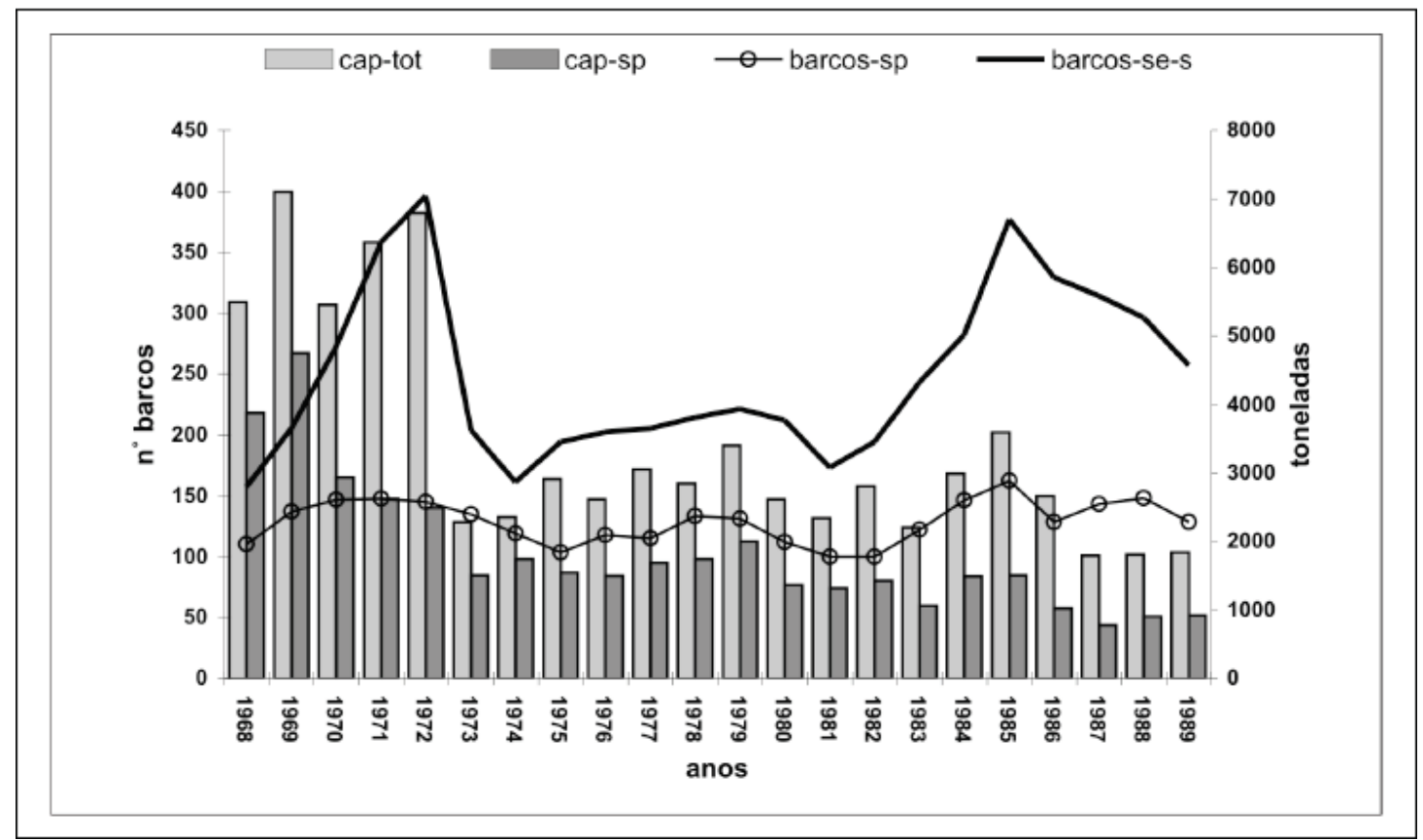

FIGURA 1 - Produção anual controlada (t) de camarão-rosa, desembarcada pela frota industrial, em São Paulo e na região Sudeste-Sul, no período de 1968 a 1989 (modificada de D'Incao et al., 2002). Cap-tot - captura total em toneladas; cap-sp - captura frota de São Paulo; barcos-sp - número de barcos em São Paulo; barcos-se-s - número de barcos no sudeste e sul.

Para cada período parcial foram calculadas e distribuídas nos sub-blocos de 10' as médias anuais de captura $(\mathrm{kg})$, de esforço de pesca (horas de arrasto), da CPUE-captura por unidade de esforço $(\mathrm{kg} / \mathrm{h})$ do camarão-rosa e de captura da fauna acompanhante desembarcada (bycatch).

Ainda para efeito de análise, os blocos de $1^{\circ}$ foram agrupados em três grandes áreas, limitadas por faixas de latitude: norte (entre $18^{\circ} \mathrm{S}$ e $23^{\circ} \mathrm{S}$ ), centro (entre $24^{\circ} \mathrm{S}$ e $25^{\circ} \mathrm{S}$ ) e sul (entre $26^{\circ} \mathrm{S}$ e $33^{\circ} \mathrm{S}$ ). Foram tabulados os totais de captura, esforço de pesca e CPUE do camarão-rosa para cada uma dessas áreas, nos períodos anuais estudados. Os dados obtidos para cada um dos quadrados foram utilizados para geração de mapas de contorno em software de SIG. O método escolhido para a interpolação dos dados foi o de natural neighbour, que cria áreas de vizinhança entre os quadrados analisados, considerando o peso 
específico de cada ponto. Foram analisados em quadrados de 10 ' os totais anuais de captura $(\mathrm{kg})$, de esforço de pesca (horas de arrasto), da CPUEcaptura por unidade de esforço $(\mathrm{kg} / \mathrm{h})$ do camarãorosa e de captura da fauna acompanhante desembarcada (rosa:bycatch), plotados a seguir nos perfis geográficos da área em estudo.

Com base nos dados da fauna acompanhante foi criada uma matriz de presença e ausência, que, posteriormente, foi submetida a uma análise de agrupamento, na intenção de identificar grupos de peixes de acordo com sua distribuição batimétrica. Essa análise teve como principal objetivo demonstrar a mudança no padrão da pescaria que inicialmente tinha o camarão-rosa como alvo exclusivo e, portanto, capturava uma fauna característica da zona costeira (40-80 metros).

\section{RESULTADOS}

As figuras 2, 3 e 4 ilustram a dinâmica de atuação da frota arrasteira estudada, com as variações observadas nas áreas explotadas e nos períodos considerados. No primeiro período (19681972), os volumes médios de captura apresentaramse maiores na área centro até o mês de abril e ao final do ano (novembro e dezembro); comportamento inverso observou-se na área sul, enquanto no norte a curva de produção configurou-se, com ascensão e decréscimo, de maio a dezembro (FIGURA 2). Considerando a média anual do período, verifica-se que $46 \%$ das capturas provieram do centro, $38 \%$ do sul e $16 \%$ do norte, com os meses de agosto a outubro respondendo pelas maiores produções. Neste qüinqüênio, pois, a frota atuou amplamente sobre a área de distribuição do recurso, concentrando esforço no centro, nos meses iniciais e finais do ano, e dividindo-se para o sul e norte nos demais (FIGURA 3). $O$ esforço de pesca médio anual foi aplicado em $55 \%$ no centro, $29 \%$ no sul e $16 \%$ no norte. Os índices médios da abundância relativa (CPUE) esclarecem a dispersão da frota no segundo semestre (FIGURA 4), pois cresceram nas três áreas, porém em maiores proporções no sul e norte, em nível tal que, nesse período, foram obtidos os maiores rendimentos históricos da pescaria.
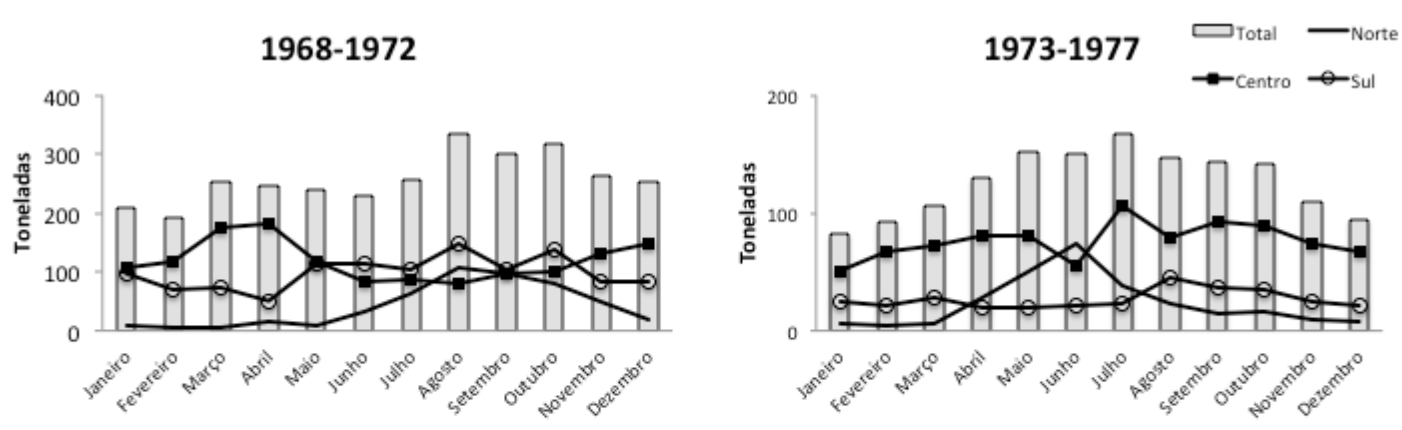

1978-1983

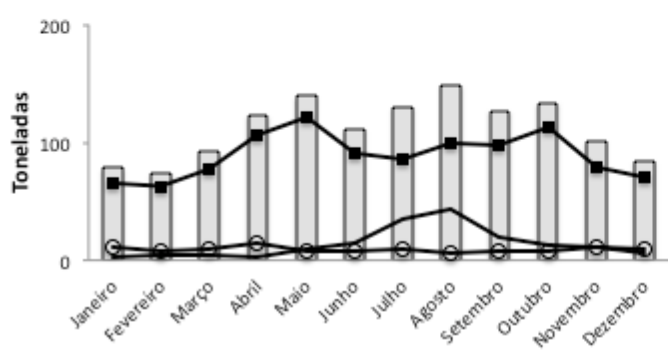

1984-1989

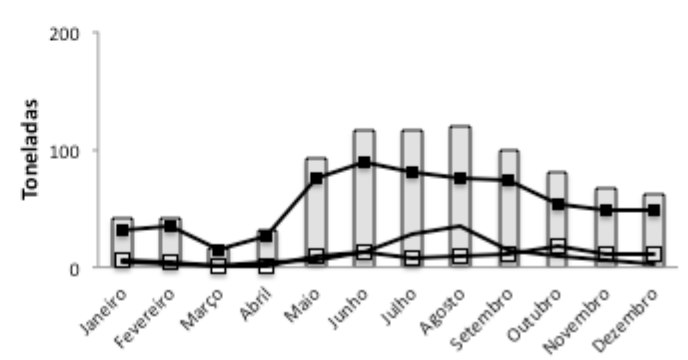

FIGURA 2 - Captura média mensal (t) de camarão-rosa, nas áreas Norte $\left(\leq 23^{\circ} \mathrm{S}\right)$, Centro $\left(24^{\circ}-25^{\circ} \mathrm{S}\right)$, Sul $\left(\geq 26^{\circ} \mathrm{S}\right)$ e área total $\left(18^{\circ}-33^{\circ} \mathrm{S}\right)$ 

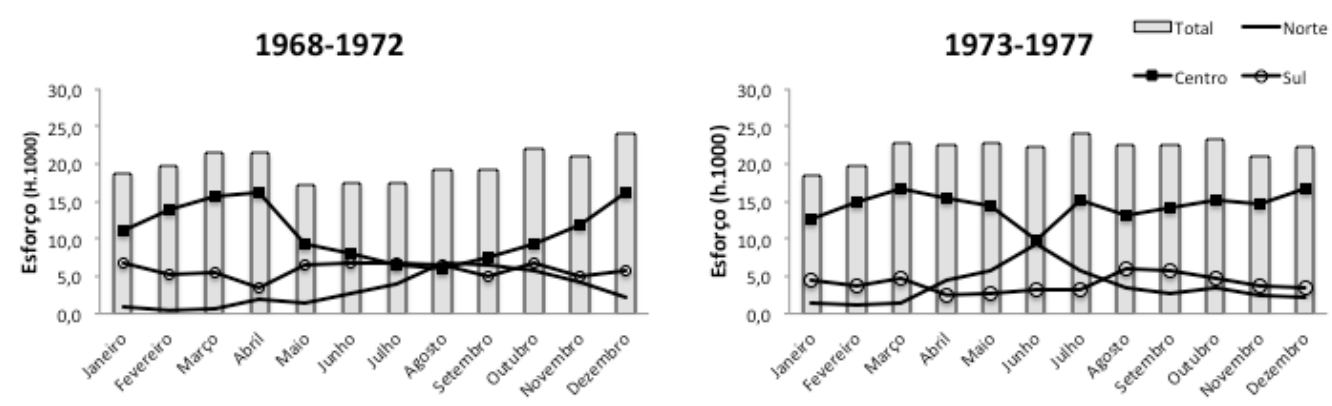

1978-1983
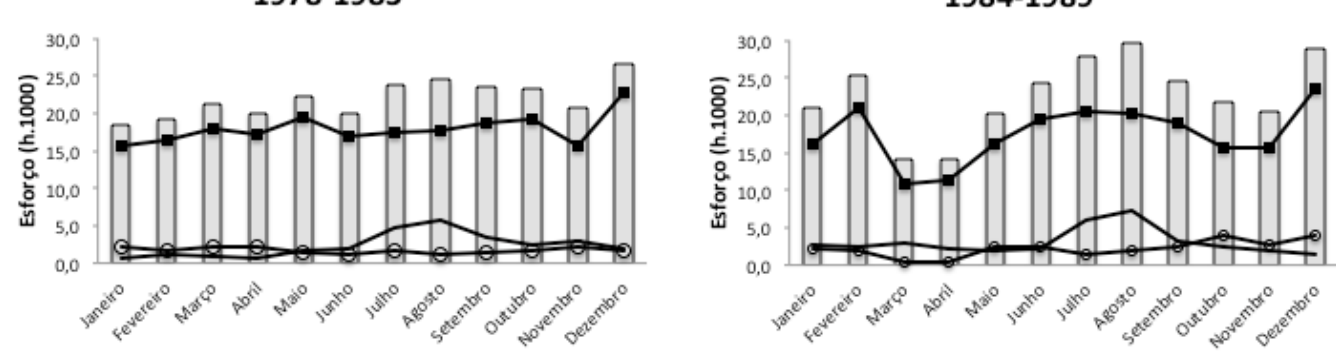

FIGURA 3 - Esforço de pesca médio mensal (h.1000) aplicado sobre o estoque de camarão-rosa nas áreas Norte $\left(\leq 23^{\circ} \mathrm{S}\right)$, Centro $\left(24^{\circ}-25^{\circ} \mathrm{S}\right)$, Sul $\left(\geq 26^{\circ} \mathrm{S}\right)$ e área total $\left(18^{\circ}-33^{\circ} \mathrm{S}\right)$

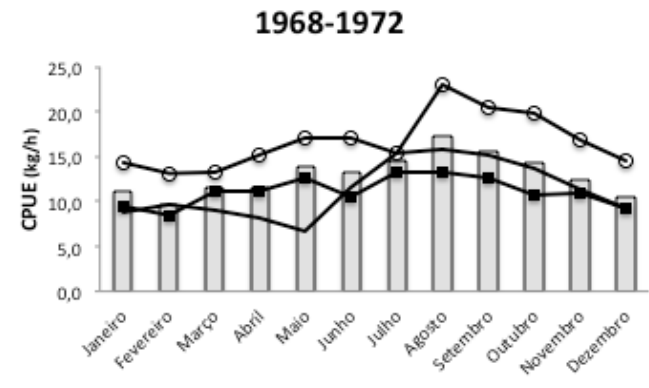

1978-1983

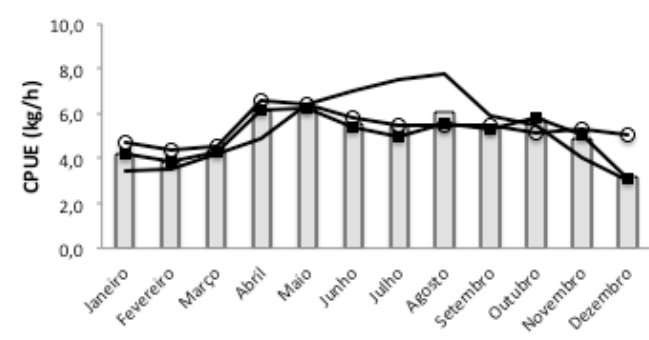

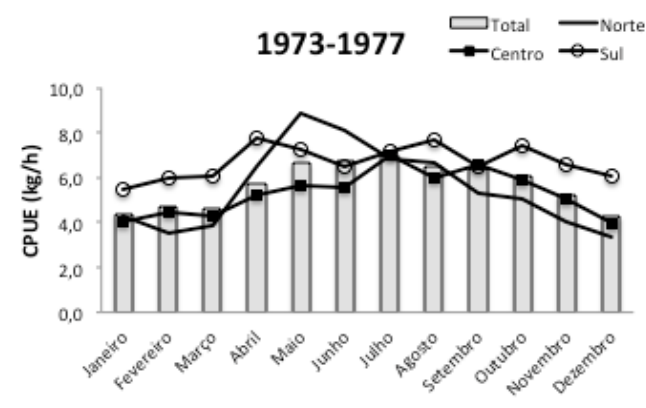

1984-1989

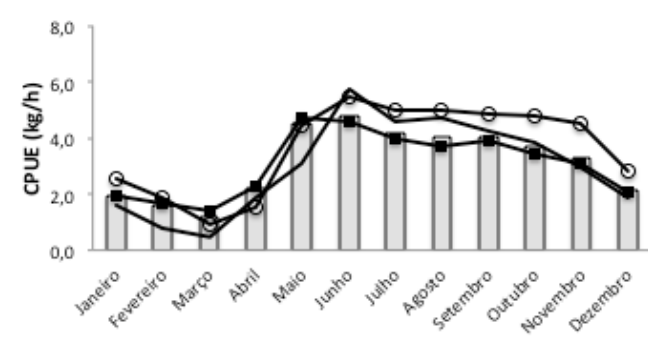

FIGURA 4 - Abundância relativa média mensal - CPUE (kg/h) do estoque de camarão-rosa, das áreas Norte $\left(\leq 23^{\circ} \mathrm{S}\right), \mathrm{Centro}^{\circ}\left(24^{\circ}-25^{\circ} \mathrm{S}\right), \mathrm{Sul}^{\circ}$ $\left(\geq 26^{\circ} \mathrm{S}\right)$ e área total $\left(18^{\circ}-33^{\circ} \mathrm{S}\right)$

O quinquênio 1973-1977 apresentou, na média anual, capturas expressivamente menores e obtidas, em sua maior parte e durante $\mathrm{o}$ ano todo, na área centro; apenas em junho foram superadas pelas do norte (FIGURA 2). As médias anuais foram da ordem de $60 \%$ no centro, $21 \%$ no sul e $19 \%$ no norte. A frota manteve-se atuando nas três áreas, porém, concentrando o esforço de pesca, nitidamente, no centro; a presença nas áreas norte e sul mostrou-se mais homogênea e menos importante que no período anterior, com exceção dos meses entre abril e julho, quando parcela pouco maior do esforço de pesca foi direcionado ao norte (FIGURA 3), em correspondência a um maior rendimento das capturas (FIGURA 4). Em termos do esforço médio anual, observou-se que $65 \%$ foi aplicado na área centro, $18 \%$ na sul e $16 \%$ na norte. 
O menor deslocamento da frota ao longo do ano estaria vinculado, provavelmente, a um decréscimo geral associado à maior homogeneidade das abundâncias, embora as áreas norte e sul tenham se mostrado um pouco superiores.

O período 1978-1983 mostrou expressiva concentração das capturas médias na zona central; somente nos meses de julho e agosto ocorreram incrementos na área norte (FIGURA 2). Nas médias anuais, observou-se que $79 \%$ das capturas provieram do centro, $12 \%$ do norte e $8 \%$ do sul. Portanto, apesar de permanecer atuando nas três áreas, a frota concentrou o esforço de pesca na região centro, com direcionamento ao norte aumentado em julho e agosto, correspondente a uma melhoria na abundância (FIGURA 3). Numericamente, o esforço médio anual foi aplicado em $82 \%$ no centro, $11 \%$ no norte e $8 \%$ no sul da área estudada. 0 menor deslocamento da frota ao longo do ano, na média deste período, seguiu a tendência observada no qüinqüênio anterior, tendo sido intensificada pelo decréscimo da abundância (FIGURA 4), de evidente homogeneidade em toda a área.

Finalmente, o período 1984-1989 mostrou capturas médias mais baixas e comportamento similar ao anterior, inclusive quanto ao incremento da área norte nos meses de julho e agosto (FIGURA 2). As médias anuais mantiveram-se em $74 \%$ (centro), 14\% (norte) e 12\% (sul). A FIGURA 3 mostra que, apesar da alta concentração no centro (77\%), a frota aplicou maior esforço de pesca nas outras áreas ( $14 \%$ ao norte e $12 \%$ ao sul), comparativamente ao período 1978-1983, dada a clara identidade e redução da abundâncias (FIGURA 4).

As figuras 5, 6, 7 e 8 mostram como variaram, nos quadrados de 10', os valores totais de captura (t) do camarão-rosa, do esforço de pesca (horas de arrasto), da abundância relativa $(\mathrm{kg} / \mathrm{h})$ e da relação $\mathrm{CPUE}_{\text {bycatch }}$ :

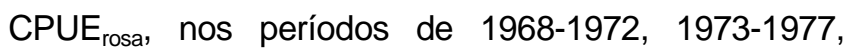
1978-1983 e 1984-1989, respectivamente.

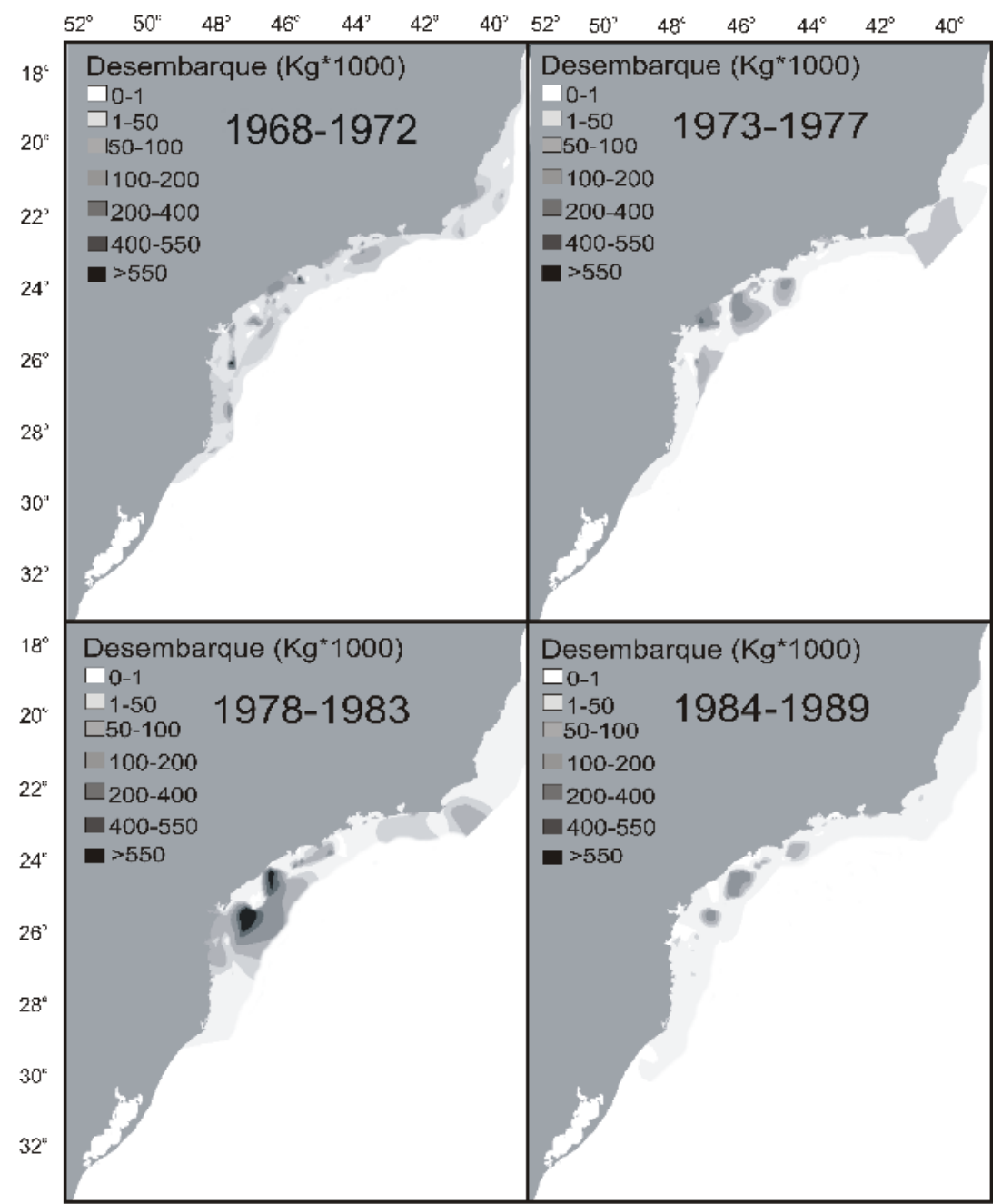

FIGURA 5 - Captura total de camarão-rosa, por bloco de 10', nas regiões Sudeste e Sul do Brasil - períodos 1968-1972, 1973-1977, 1978-1983 e 1984-1989. 


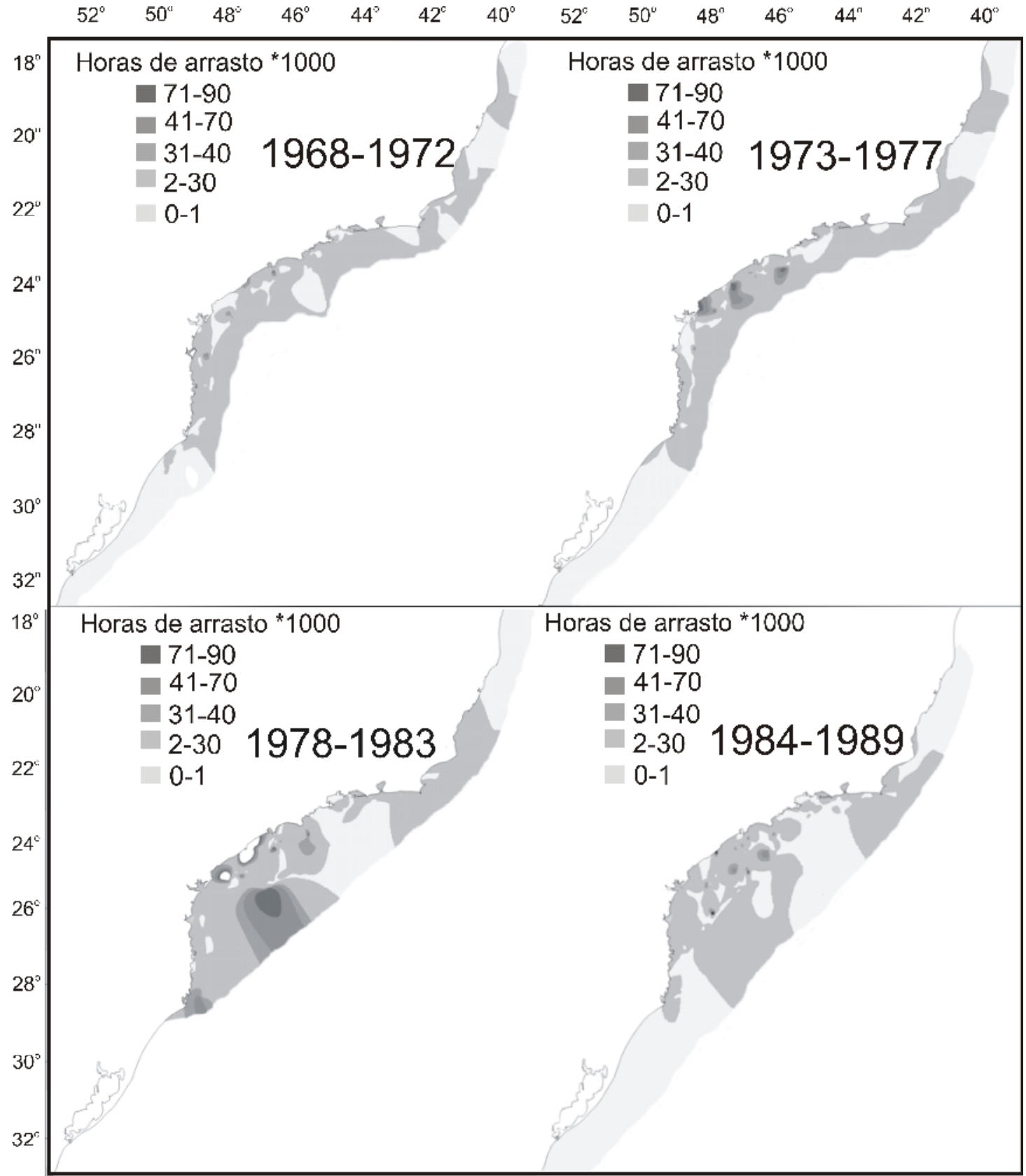

FIGURA 6 - Esforço de pesca total (horas de arrasto*1000), aplicado sobre o estoque de camarão-rosa, por bloco de 10', nas regiões Sudeste e Sul do Brasil - períodos 1968-1972, 1973-1977, 1978-1983 e 1984-1989 


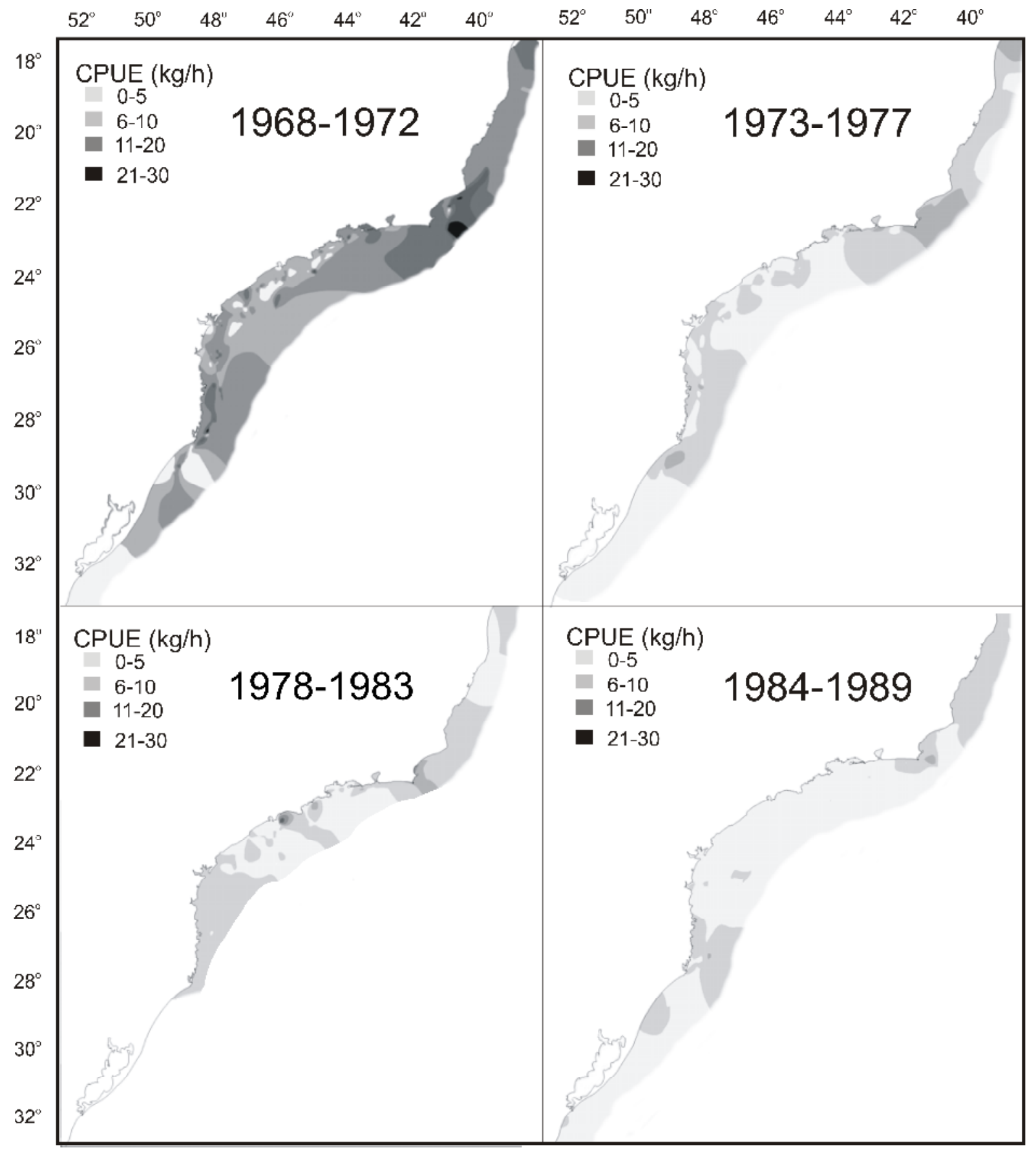

FIGURA 7 - Abundância relativa média - CPUE (kg/h), do estoque de camarão-rosa, por bloco de 10', nas regiões Sudeste e Sul do Brasil períodos 1968-1972, 1973-1977, 1978-1983 e 1984-1989 


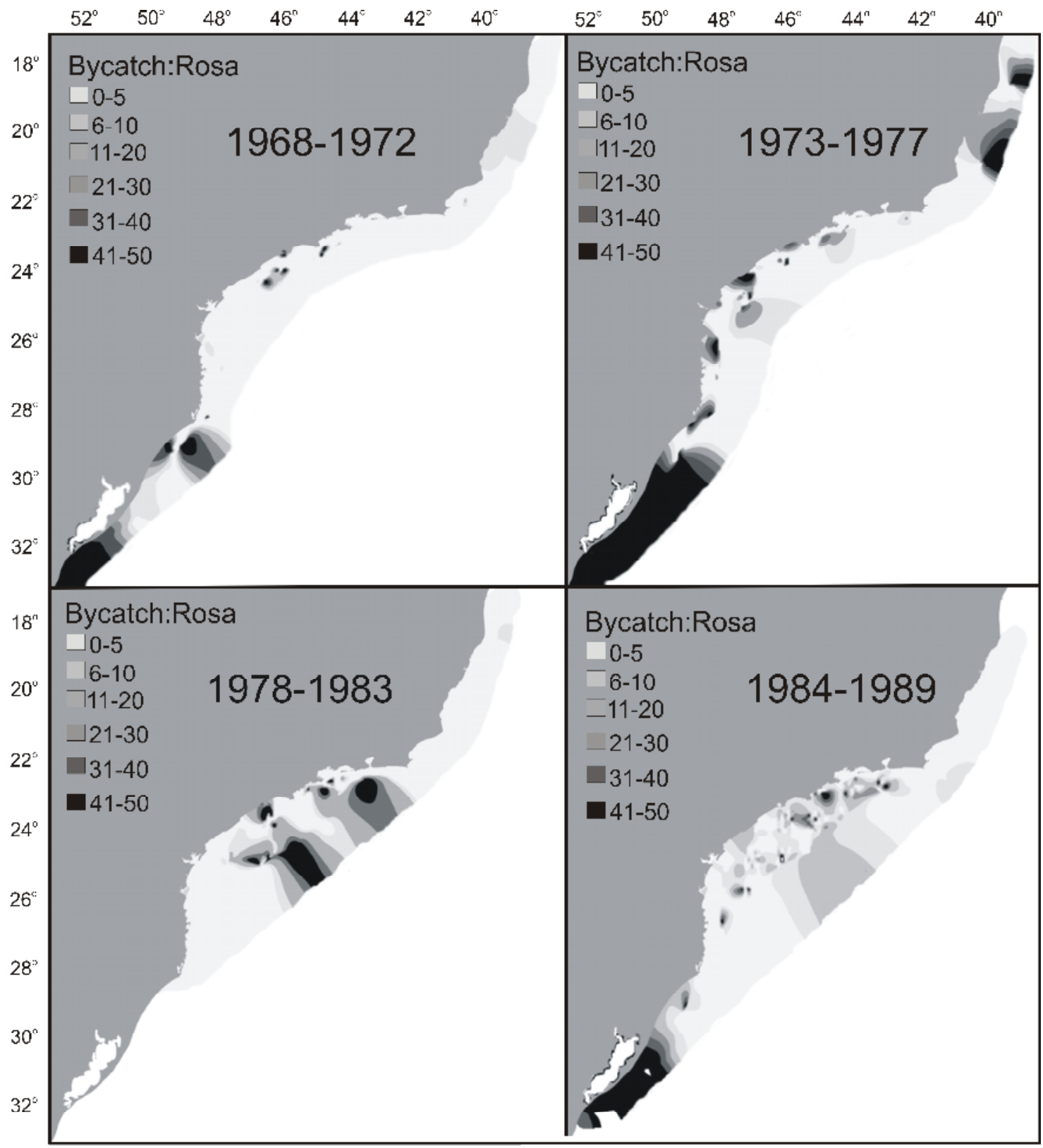

FIGURA 8 - Relação CPUE bycatch: CPUE rosa da pescaria do camarão-rosa, por bloco de 10', nas regiões Sudeste e Sul do Brasil períodos 1968-1972, 1973-1977, 1978-1983 e 1984-1989.

A Figura 5 evidencia, para o primeiro período, ampla distribuição das capturas, as quais se estenderam desde o Rio Doce-ES até a altura da Barra do Rio Grande-RS, mantendo-se restritas à zona costeira. Os maiores volumes ocorreram em áreas estreitamente relacionadas aos principais criadouros do camarão-rosa. O valor médio por subbloco $\left(10^{\prime}\right)$ foi de $65( \pm 14) t$, as capturas totais para o período superaram a $15000 \mathrm{t}$, observando-se os valores mais altos (> $350 \mathrm{t}$ ) no entorno da llha da Queimada Grande-SP, diante de São Francisco do Sul-SC e proximidades da Ilha do Arvoredo-SC. Cabe destaque também às regiões de Cabo Frio e Angra dos Reis (RJ), Iguape-Cananéia (SP), Paranaguá (PR) e Laguna (SC). Este foi o período com os mais expressivos resultados históricos da pescaria.

O perfil 1973-1977 apresenta, aproximadamente, a mesma distribuição do anterior; porém, as capturas mostraram-se menos expressivas (14000) e a área varrida diminuiu nos extremos, norte e sul, concentrando-se entre Cabo Frio e Laguna. As principais sub-áreas mantiveram-se inalteradas, porém mais restritas, pois os maiores volumes totais não atingiram os maiores patamares entre 750 e $950 \mathrm{t}$. 
O perfil 1978-1983 ainda aponta concentração das capturas totais $(8.000 \mathrm{t})$ nas áreas dos tradicionais pesqueiros anteriormente identificados com poucos sub-blocos apresentando volumes expressivos (>550 t).

Em 1984-1989, tornou-se mais evidente a redução das capturas (5300 t) e dispersão das mesmas por áreas de profundidade maior, fato que se torna evidente já durante o terceiro quinquênio. Os maiores volumes capturados são baixos (> $70 \mathrm{t}$ ) e, provieram também das áreas um pouco mais ao sul, como a fronteira lguape-Cananéia (em torno da llha do Bom Abrigo) e Paranaguá.

A figura 6 apresenta, para o período de 19681972, uma distribuição relativamente homogênea do esforço de pesca anual total, aplicado ao longo da área de operação da frota em estudo. Tal esforço não ultrapassou o nível de 30000 horas de arrasto e manteve-se restrito à área costeira.

O perfil 1973-1977 mostra o esforço de pesca em plano mais elevado (71000-90000 horas de arrasto) e uma evidente concentração da atividade sobre os pesqueiros tradicionais acima citados.

No período 1978-1983 ocorreu maior concentração nessas áreas, observando-se, na média anual, o máximo de 71000-90000 horas de arrasto na região fronteira a Iguape-Cananéia e Paranaguá, coincidindo com as áreas de maior captura mostradas, para o mesmo perfil, na Figura 5. Por outro lado, são observados valores altos de esforço em pontos já afastados da costa, chegando até o nível de 71000-90000 horas de arrasto. É importante notar que este esforço não foi traduzido em capturas de camarão-rosa (FIGURA 5).

O perfil 1984-1989 apresenta ampla distribuição do esforço de pesca na plataforma continental, apesar de as maiores concentrações terem sido mantidas nas áreas tradicionais de pesca, nestes casos em nível não superior a 70000 horas de arrasto. Observa-se aqui uma nítida expansão da área varrida pela frota, sem repercussão nas capturas da espécie-alvo da pescaria.

A figura 7 mostra, para o período 1968-1972, os maiores índices de abundância relativa alcançados em toda a área de distribuição do camarão-rosa, explotada pela frota paulista. Salientam-se o norte da região Sudeste-Sul (Cabo Frio e São João da Barra -
RJ), com expressivos valores (25-30 kg/h) e o sul, na costa de Santa Catarina, com abundâncias até 15-19 $\mathrm{kg} / \mathrm{h}$, particularmente frente a Itajaí e entre Laguna$\mathrm{SC}$ e Torres-RS, ao nível citado para o norte. A área centro apresentou índices menores, por receber um esforço de pesca mais intenso (FIGURA 6).

O perfil 1973-1977 apresenta uma flagrante redução da abundância em toda a amplitude de distribuição do recurso; alguns poucos pontos sobressaem com valores mais elevados, mesmo assim não ultrapassando $10-14 \mathrm{~kg} / \mathrm{h}$, nas regiões de Cabo Frio-Macaé/RJ e Torres/RS). A maior parte, porém, mostra-se homogênea, no intervalo de 6 a 10 $\mathrm{kg} / \mathrm{h}$.

O perfil 1978-1983 repete, em termos de valores, o quadro do período anterior, com a diferença de que as duas únicas áreas a atingir abundâncias relativas médias de $11-20 \mathrm{~kg} / \mathrm{h}$, localizam-se frente a Santos e Paranaguá.

O período1984-1989 evidencia nova queda nos índices de abundância, pois os valores mais elevados (6-10 kg/h), registrados em poucos pontos, eram maioria no perfil anterior. Apenas em um ponto isolado, diante do Rio de Janeiro, foi registrado índice médio de 11-20 kg/h. A abundância mostra-se homogênea, porém nos valores mais baixos da série histórica examinada.

A figura 8 apresenta, para o período 19681972, capturas de fauna acompanhante bem distribuídas ao longo da área total, com valores na sua maioria entre 0-5 (CPUE bycatch $_{\text {:CPUE }}$ rosa).

O perfil 1973-1977 mostra um incremento na retenção a bordo e desembarque da fauna acompanhante, com alguns pontos alcançando níveis máximos de bycatch (>41). Comparando com os do camarão-rosa à mesma época (FIGURA 5) pode-se inferir que a redução destes levou a uma compensação no aproveitamento do bycatch.

O perfil 1978-1983 reforça esta inferência e, ao mesmo tempo, explica os valores mais elevados do esforço de pesca observado em áreas mais afastadas da costa (FIGURA 6). O perfil 1984-1989 apresenta a ampla área varrida pela frota, desde a costa até profundidades além dos limites de ocorrência do camarão-rosa, com amplo aproveitamento da fauna acompanhante em toda a longitude alcançada. Dessa forma, a evolução da captura e desembarque da 
fauna acompanhante foi ganhando importância após o primeiro qüinqüênio e mostrou-se em franca ascensão na década de 1980 .

A análise de agrupamento (Tabela 1; FIGURA 9) permitiu identificar dois grupos principais de fauna acompanhante, que estão associados à distribuição batimétrica das espécies. O primeiro agrupamento $(A)$ é composto por espécies que habitam áreas costeiras, e que correspondem aos fundos tradicionais da pesca camaroneira. Este grupo costeiro pode ser subdividido em dois subgrupos (A1 e A2). O subgrupo A1 é caracterizado pela presença de espécies bem costeiras, onde são observados camarões comerciais como sete-barbas ( $X$. kroyeri), branco ( $L$. schmitti) e barba-ruça ( $A$. longinaris). O subgrupo A2 é caracterizado por espécies que habitam áreas mais afastadas da costa, que pode ser considerada como a área principal de pesca de camarão-rosa adulto. São observados nessa área as duas espécies de camarão-rosa ( $F$. brasiliensis e $F$. paulensis) e camarão-santana ( $P$. muellerı). O segundo agrupamento principal (B) é caracterizado por espécies que habitam maiores profundidades, fora da região tradicional de pesca do camarão-rosa. São observados nesse agrupamento duas espécies de crustáceo de valor econômico ( $P$. americanus e $M$. rubellus), que provavelmente foram alvo desta pescaria, considerada para frota, como alternativa aos períodos de defeso e à queda de abundância da pesca do camarão-rosa. A captura desta fauna é consequência da queda de rendimento da pescaria. $A$ frota passou a explorar outros recursos, o que levou a fauna acompanhante não mais condizer com aquela dos fundos tradicionais de pesca de camarão-rosa.

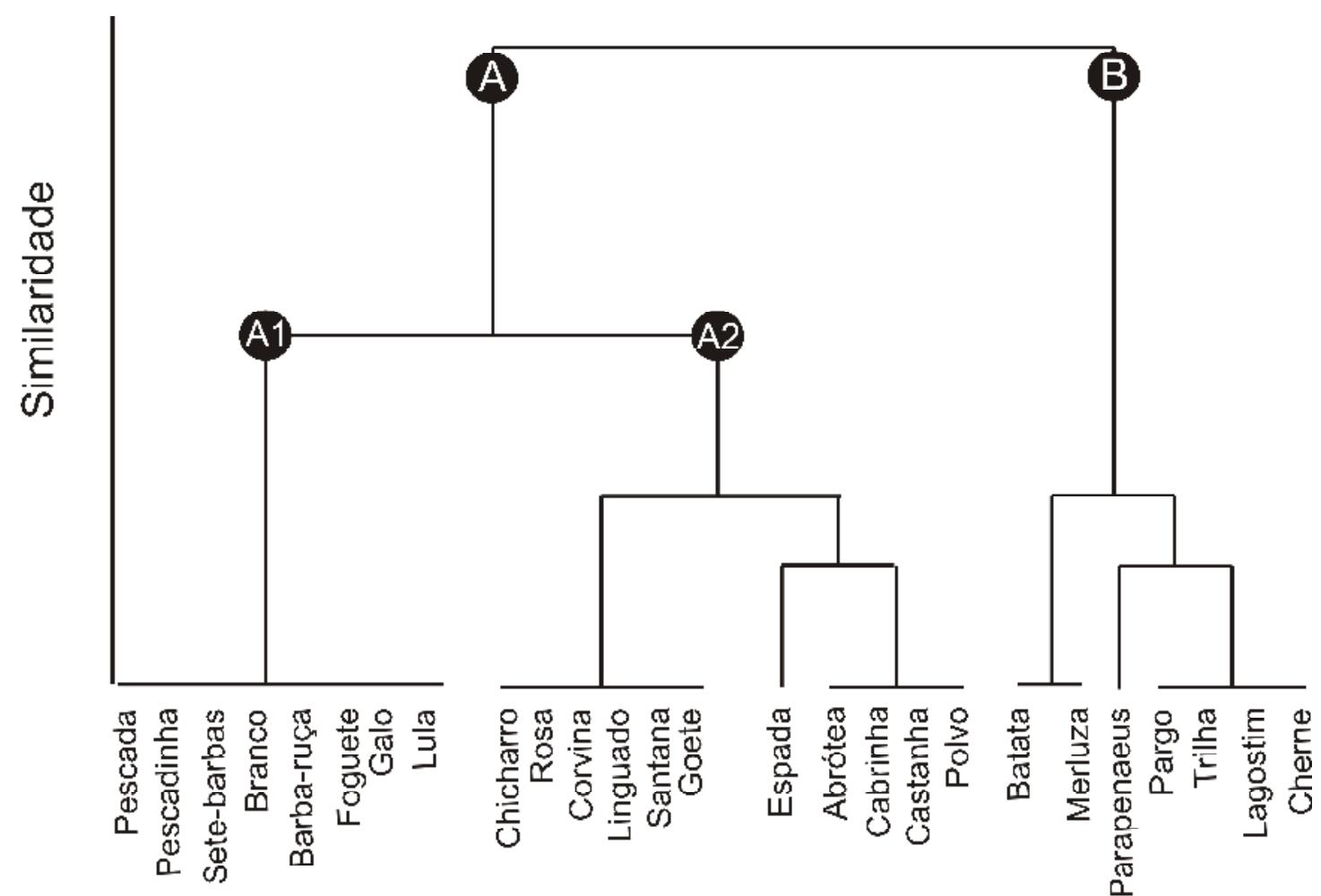

FIGURA 9. Análise de agrupamento relativo à presença de espécies que compõe os desembarques da pesca da frota camaroneira de São Paulo. O grupo A é formado por espécies costeiras (da costa até a isóbata de $80 \mathrm{~m}$ ). O subgrupo A1 representa as espécies pescadas, preferencialmente, entre a costa e a isóbata de 30 metros. O subgrupo A2 representa as espécies capturadas, preferencialmente, entre as isóbatas de 30 e 80 metros. O grupo B é composto por espécies que ocorrem, principalmente, fora da isóbata de 80 metros. 
Tabela 1. Listagem das espécies da fauna acompanhante desembarcadas e consideradas na análise de agrupamento.

\begin{tabular}{ll} 
Nome vulgar & Espécie \\
PEIXES & \\
Pescada & Cynoscion guatucupa \\
Pescada-foguete, Pescadinha & Macrodon ancylodon \\
Galo & Selene setapinis \\
Xixarro & Trachurus lathami \\
Corvina & Micropogonias furnieri \\
Linguado & Paralichthys orbignyanus, P. patagonicus \\
Goete & Scinoscium jamaicensis \\
Espada & Trichiurus lepturus \\
Abrótea & Urophycis brasiliensis \\
Cabrinha & Prionotus punctatus \\
Castanha & Umbrina canosai \\
Batata & Lopholatilus villarii \\
Merluza & Merlucius sp. \\
Pargo & Lutjanus purpureus \\
Trilha & Mullus argentinus. \\
Cherne & Epinephelus sp \\
CRUSTÁCEOS & \\
Camarão-sete-barbas & Xiphopenaeus kroyeri \\
Camarão-branco & Litopenaeus schmitti \\
Camarão-barba-ruça & Artemesia longinaris \\
Camarão-santana & Pleoticus muelleri \\
Camarão-rosa & Farfantepenaeus brasiliensis, F. paulensis \\
Parapenaeus & Parapenaeus americanus \\
Pitu & Metanephrops rubellus \\
MOLUSCOS & \\
Lula & Loligo sp. \\
Polvo & Octopus sp. \\
\hline
\end{tabular}

\section{DISCUSSÃO}

As estimativas indicam que a frota camaroneira controlada que efetuou desembarques em São Paulo constituiu, na média, cerca de $50 \%$ das unidades operantes no sudeste e sul do Brasil. Esta constatação demonstra a importância da frota paulista na evolução da pesca do camarão-rosa na região, fortalecendo a posição de que sua atividade pode ser considerada representativa do total da pescaria de camarão-rosa do sudeste-sul. Conceito utilizado por Valentini et al. (1991) e D'Incao et al. (2002) quando da análise do estoque, ao extrapolarem as estimativas da abundância relativa obtida pela frota paulista para o total da atividade pesqueira. Os resultados obtidos sobre a distribuição do esforço de

pesca reforçam esta opção ao demonstrar que a frota atuou sobre toda a área de distribuição do estoque e que seus desembarques apresentam boa correspondência com o obtido pelo total da frota.

Segundo registros do DEFOP/SUDEPE em setembro de 1987 existiam 300 embarcações devidamente licenciadas para a pesca do camarãorosa, alem disso, existiam 25 barcos com licenças prévias de construção concedidas pela SUDEPE em Santa Catarina e estimava-se a existência de 78 unidades em operação sem qualquer tipo de licença. Assim sendo, podia-se chegar a um numero de 378 barcos operando na área com perspectivas de subir com a incorporação dos barcos em construção (SUDEPE, 1987). Estes valores vinham de encontro com as estimativas realizadas a partir dos dados de 
captura e esforço, de vez que nos anos de 1985, 1986 e 1987 estimou-se a frota atuante em mais de 300 unidades.

O importante incremento da produção e do tamanho da frota atuante no sudeste-sul no período 1968-1972 foi uma resposta aos incentivos fiscais à pesca resultantes da promulgação do Decreto Lei 221 de fevereiro de 1967. Estes incrementos foram causados, principalmente, pelo estabelecimento de uma frota atuante no Estado de Santa Catarina e ampliação das frotas dos demais estados do sudestesul, que são evidenciados pelo aparecimento dos primeiros registros de desembarque da frota comercial em Santa Catarina e aos incrementos de produção no Rio de Janeiro e São Paulo nos anos de 1968 a 1972 (D'Incao et al., 2002). O período de estabilidade de produção está relacionado à estabilização do tamanho da frota atuante (em torno de 200 unidades) observado a seguir e que perdurou até 1983. Prevaleceu nesse período a Portaria SUDEPE N-456 de setembro de 1974, que instituiu a obrigatoriedade do licenciamento para a pesca do camarão-rosa para barcos com TBA superior a $5 \mathrm{t}$, restringindo-a aqueles inscritos no RGP-SUDEPE Registro Geral da Pesca e aos já construídos ou em construção autorizada até aquela data. A Portaria SUDEPE N-048 de outubro de 1983 veio reforçar a anterior com a restrição de substituição de embarcações e a cassação das licenças daquelas que não comprovassem por documentação oficial um número de desembarques igual ou superior a 10.

Seguiu-se a esse período um incremento desordenado da frota sem um proporcional aumento de produção. Tal situação foi provocada pela revogação da portaria anterior pela Portaria SUDEPE $\mathrm{N}-53$ de dezembro de 1984 que no cômputo geral concedeu uma ampla anistia a todas as embarcações que se encontravam em operação em situação irregular perante a portaria anterior, alem de permitir a concessão de novas permissões especiais, por ato do Superintendente da SUDEPE, fato evidenciado pela construção das 25 embarcações novas no estado de Santa Catarina, acima citados. Os resultados demonstram que a introdução de embarcações novas como conseqüência dessa portaria deu-se de forma expressiva.
Compreende-se a expansão da frota observada no início da década de 1970, como produto da estruturação da pescaria industrial do camarão-rosa cujo estoque encontrava-se nitidamente subexplotado; da abertura do mercado de exportação para o camarão-rosa do sudeste-sul e da disponibilidade de recursos oriundos dos incentivos fiscais. Ao contrário, a segunda expansão, ocorrida em um período de euforia econômica no país, resultado imediato do chamado "Plano Cruzado", denota total irresponsabilidade do órgão gestor da pesca, pois o estoque não demonstrava naquela época capacidade de resposta positiva a um aumento do esforço. A comunidade científica através do Grupo Permanente de Estudos de Camarões do SudesteSul, instituído pela própria SUDEPE, em suas reuniões anuais, manteve, persistentemente, como uma das recomendações ao ordenamento da pescaria a redução da frota atuante no sudeste-sul ao máximo de 200 unidades (CEPSUL-IBAMA, 1984, 1985, 1986, 1987, 1991, 1992). Entretanto, portaria normativa editada posteriormente (IBAMA $\mathrm{N}$ 1345/dezembro de 1989;) propiciou nova anistia às embarcações não permissionadas atuantes na pesca do camarão-rosa. Esta foi revogada pela portaria IBAMA N-97/agosto de 1997.

O período de 1968-1972 caracterizou-se por apresentar as maiores capturas e abundâncias da série analisada, em virtude dos estoques de camarãorosa encontrarem-se sub-explotados e com a frota pesqueira em expansão. $O$ deslocamento da frota fez-se, claramente, a partir da área centro (em frente à costa de São Paulo) em direção ao norte e ao sul, em busca de maiores rendimentos na pescaria. Nesse período manifestou-se de forma clara a interdependência entre o esforço de pesca aplicado no centro e no norte, vinculada à abundância relativa temporal nessas áreas. O mesmo quadro não se aplica a área sul, para onde, a partir de valores excepcionais da abundância média, refletida nos altos níveis de captura, unidades da frota de São Paulo e Santa Catarina operaram quase homogeneamente durante todo o período, efetuando desembarques em São Paulo.

No período de 1973-1977 a configuração do deslocamento da frota paulista manteve-se semelhante ao período anterior com manifesta 
redução nos níveis de captura e abundancia relativa nas três áreas. Cabe destacar que no início deste período (1973) ocorreu a primeira grande crise, da década, no custo do petróleo o que inibiu o afastamento das frotas pesqueiras de camarões e de outros recursos, de suas bases de atuação. Nos períodos subseqüentes tal situação se tornou ainda mais evidente agravada que foi pela gradativa redução da abundância ao longo de toda área de distribuição do estoque. Note-se que o esforço aplicado sobre o recurso manteve-se alto apesar da drástica redução na rentabilidade da pescaria.

O panorama mostrado pela frota corrobora e explica de forma bastante evidente os resultados da avaliação dos estoques apresentada por D'Incao et.al. (2002), onde são mostrados três patamares, significativamente distintos, de rendimento dos estoques, correspondendo aos períodos de 19651972 (alta abundância e crescimento do esforço), 1973-1986 (equilíbrio relativo do esforço, traduzido pela manutenção do tamanho da frota atuante) e 1987-1995 (aumento desordenado do esforço, com queda na abundancia e correspondente repercussão na diminuição na captura).

A partir de 1984 foi implantado pela SUDEPE (Portaria N-50 de outubro de 1983), por reivindicação do setor produtivo, um período de defeso (paralisação da pescaria) com os objetivos de proteger o recrutamento e, portanto, a recuperação do estoque adulto, diminuir o esforço de pesca e maximizar economicamente a produção. A análise de Valentini et al. (1991) sobre inconstância das diretrizes que nortearam as portarias anuais do defeso, tornaram ineficaz esta medida, que se, efetivamente cumprida, e que se mantivesse estável o tamanho da frota camaroneira, poderia ter pelo menos amenizado a redução dos estoques, mantendo-o no nível do período de equilíbrio observado entre os anos de 1973 a 1983. A figura 3 mostra, no período 18941989, a ocorrência de capturas nos meses de defeso (fevereiro-maio) o que denota claramente a burla à legislação.

A distribuição da captura, esforço e da abundancia relativa (FIGURAS 5, 6 e 7) ao longo da costa do sudeste-sul mostra concentrações importantes das mesmas nas áreas imediatamente próximas aos principais criadouros, mantendo-se evidentes mesmo após a diminuição do estoque. $\mathrm{O}$ esforço de pesca tem distribuição diferenciada quando comparada com as áreas de ocorrência do camarão-rosa. Este fato inicia seu aparecimento no período 1978-1983 e ganha importância no período seguinte. Nos períodos iniciais da série estudada, a rentabilidade econômica proporcionada pelo camarão-rosa sustentava a pescaria determinando um altíssimo nível de rejeição a bordo da fauna acompanhante, com aproveitamento apenas de recursos de valor comercial importante. Com a diminuição dos rendimento do camarão-rosa, a fauna acompanhante passou a ganhar importância na pescaria a ponto de garantir a sustentabilidade econômica da mesma (D'Incao et al., 2002). Esse fato está evidenciado nas figuras 6 e 8 , que mostram a expansão da área de atuação da frota camaroneira muito além dos limites da ocorrência do camarãorosa, em busca de outros recursos demersais. Segundo Perez et al. (2001) a frota de arrasteiros duplos licenciada para a pesca do camarão-rosa e fauna acompanhante vem aplicando, na atualidade, um esforço de pesca desordenado e oportunista sobe recursos de plataforma já plenamente explotados ou mesmo sobre-explotados; dentre estes incluem-se espécies componentes da fauna acompanhante do camarão-rosa (lulas, linguado, peixe-porco e outros) que, eventualmente, se transformam em espéciesalvo neste pescaria, e também estoques disponíveis à pesca de arrasto, mas que não se caracterizam como "bycatch" do camarão (camarões santana e barbaruça). Além disso, a frota camaroneira tem mostrado um crescente direcionamento do esforço para recursos não anteriormente explotados, principalmente, nas áreas de plataforma externa e talude, de forma igualmente concentrada (peixe-sapo, congrio-rosa, emplastro e outros). Configura-se assim, a transformação da pescaria do camarão-rosa de mono em multiespecífica (D'Incao et al. (2002).

Os resultados desse trabalho demonstram que essa tendência de diversificação dos alvos da frota camaroneira, na realidade, teve início na década de 80 , intensificando-se durante a segunda metade. A partir do terceiro qüinqüênio (1978-1983) observa-se que a frota de São Paulo expandiu sua área de atuação em direção a profundidades maiores, coincidindo com a implementação dos períodos de 
defeso da pesca do camarão-rosa e ao incremento desordenado do esforço de pesca. Nessa ocasião, a frota procurou alvos alternativos fora da área de ocorrência do camarão-rosa, notadamente, direcionando o esforço para a pesca do pitu $(M$. rubellus). Na década de 80 , mas, principalmente, durante o quarto qüinqüênio considerado na análise (1984-1989), além da expansão da área de pesca para maiores profundidades, deve ser destacado o incremento dos desembarques dos camarões barbaruça $(A$. longinaris) e santana ( $P$. muelleri) (D'Incao et al., 2002). Este fato significou um deslocamento para a costa do Rio Grande do Sul, principalmente, no período entre outubro e fevereiro.

\section{REFERÊNCIAS}

CEPSUL/IBAMA. 1991. Relatório da Reunião do Grupo Permanente de Estudos sobre Camarões das Regiões Sudeste e Sul. Itajaí, Coleção Meio Ambiente. Série Estudos - Pesca, Brasília, 36p.

CEPSUL/IBAMA. 1992. Relatório da Reunião Técnica sobre Camarões das Regiões Sudeste e Sul. Itajaí, 18p.

D'INCAO, F.; VALENTINI, H. e RODRIGUES, L.F. 2002. Avaliação da pesca de Camarões das Regiões Sudeste e Sul do Brasil. 1965-1999. Atlântica, Rio Grande, 24(2):103-116.
PEREZ, J.A.A.; PEZZUTO, P.R.; RODRIGUES, L. F.; VALENTINI, H. e VOOREN, C. M.. 2001. Relatório da Reunião Técnica de ordenamento da pesca de arrasto nas Regiões Sudeste e Sul do Brasil. In: PEZZUTO, P.R.P., PEREZ, J.A.A.; RODRIGUES, L.F. \& VALENTINI, H., Reuniões de ordenamento da pesca demersal nas Regiões Sudeste e Sul do Brasil: 2000 - 20001. Notas Técnicas da FACIMAR.UNIVALI. Itajaí. 5: 3-34.

SUDEPE/PDP. 1974. Relatório do grupo do camarão-rosa. In: Relatório da Primeira Reunião do Grupo de Trabalho e Treinamento sobre Avaliação de Estoques. Série Documentos Técnicos. Brasília, 7:35-48.

SUDEPE/PDP. 1984. Relatório da Reunião do Grupo Permanente de Estudos sobre Camarões das Regiões Sudeste e Sul, Itajaí, $59 p$.

SUDEPE/PDP. 1985. Relatório da Reunião do Grupo Permanente de Estudos sobre Camarões das Regiões Sudeste e Sul, Itajaí, $35 p$.

SUDEPE/PDP. 1986. Relatório da Reunião sobre Administração da Pesca de Camarões das Regiões Sudeste e Sul, Itajaí, 16p.

SUDEPE/PDP. 1987. Relatório da Reunião do Grupo Permanente de Estudos sobre Camarões das Regiões Sudeste e Sul, Itaja, $27 p$.

VALENTINI, H, F D'INCAO, LF RODRIGUES, JE REBELO NETO, E RAHN. 1991a. Análise da pesca do camarão-rosa $(P$. brasiliensis e $P$. paulensis) nas regiões Sudeste e Sul do Brasil. Atlântica, Rio Grande, 13(1):143-157.

Submetido $-21 / 12 / 2011$

Aceito $-14 / 03 / 2012$ 
